\title{
Analysis and occurrence of residues of the hormones estriol, 17 $\alpha$ - ethinylestradiol and 17 $\beta$-estradiol in urban water supply by HPLC-DAD
}

\author{
Nádia Hortense Torres ${ }^{1 *}$, Luiz Fernando Romanholo Ferreira ${ }^{1}$, Juliana Heloísa Pinê \\ Américo $^{2}$, Graziela Cristina Rossi de Moura Andrade ${ }^{1}$, Rosana Maria de Oliveira \\ Freguglia $^{1}$, Valdemar Luiz Tornisielo ${ }^{1}$ \\ ${ }^{1}$ Laboratory of Ecotoxicology, Center of Nuclear Energy in Agriculture, University of São Paulo. Centenário Avenue, 303, \\ Postal Code: 13416-000, Piracicaba, São Paulo, Brazil. \\ ${ }^{2}$ Center of Aquiculture of Unesp - Street Prof. Paulo Donato Castellane, no number, Postal Code: 14884-900 Jaboticabal, São \\ Paulo, Brazil.
}

\begin{abstract}
Hormones 17a-ethinylestradiol, 17ß-estradiol and estriol were analyzed in urban water supply due to the concern about the problem associated with the presence of these compounds in water bodies. The aims of this project were adapt, validate analytical methodology and monitor these hormones in drinking water. Results showed that the limits of detection, linearity, regression coefficients and recoveries were suitable for the method and no contamination was detected in samples analyzed.
\end{abstract}

Keywords - drinking water estriol, 17ß-estradiol, 17a-ethynilestradiol, liquid chromatography

\section{INTRODUCTION}

Hormones are considered emerging micropollutants [1] and the environmental unbalance caused by these hormones, their distribution and behavior in different environmental levels have had great relevance recently. The introduction of these drugs to the environment stems from a combination of several factors, such as: the quantity produced; the strength (quantity, frequency and duration); efficiency of excretion of conjugated compounds and their metabolites [2]; capacity of adsorption/desorption in soil and metabolic decay in water treatment. The amount of drugs and metabolites incorporated into the environment are low, however their continuous disposal into the environment increases their concentration over time [3] and may cause adverse effects on aquatic and terrestrial organisms [4].

These residual hormones have persistent physicalchemical properties, are lipophilic, bioacumulative and have low pressure steam, facilitating their spread in environment [1,5] and are also considered endocrine disruptors [6]. Because some endocrine disruptors are fat soluble, high concentrations of these compounds can accumulate in meat, fish, eggs and dairy foods $[7,8]$.

The hormone $17 \beta$-estradiol (E2), used in hormonal replacement therapies [5], for example, was found in several types of meat (beef, pork, poultry, fish), milk and dairy products, eggs and plants (grasses and vegetables) [9]. The E2 and estrone (E1) were also found in aquatic

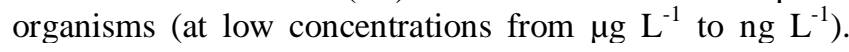
These drugs are designed to keep persistent properties, and a proportion of the drug from $50-90 \%$ is excreted unaffected into the sewage, remaining in the environment [10].

In humans and animals, E2 is oxidized in the liver, which is quickly oxidized into estrone, which is converted into estriol, is the main product of excretion [11]. The hormone E3 is the main steroid produced during pregnancy and its concentration in the plasma and urine increases constantly during pregnancy $[5,8]$. Because the hormones EE2, E2 and E3 have low vapor pressure, they are compounds that also have hydrophobicity, thus contributing with the reduction in concentrations of these compounds in the aqueous phase, which may increase their sorption in the soil or sediment [12]. However, oestradiol and ethinylestradiol were found in samples of water supply at concentrations above $\mathrm{ng} \mathrm{L}^{-1}[10]$.

The presence of E2 (6-66 $\left.\mathrm{ng} \mathrm{L}^{-1}\right)$ has also been reported in groundwater near areas with high density of livestock (Peterson et al. 2000). However, contamination of surface water occurs mainly through sewage treatment plants (STPs) [13], once water returns to the supply system without complete removal of contaminants. Besides E2, EE2 also receives special attention because it is continuously excreted into the sewage system, so it is not completely removed at the STPs [8]. Research shows that the estrogen E2 is highly responsible for estrogenic activity in effluents at STPs [14], and it is found in soil and water springs in some countries [14,15] which are mostly used as source of drinking water.

However, decontamination of drinking water will only be attained with the use of new processes for the removal of these compounds [10] such as ozonation, filtration with activated carbon, reverse osmosis, reverse electrodialysis and chlorination. One more affordable techinque is to artificially increase groundwater resources [16]. The use of water contaminated with hormones for human consumption is associated with a decline in sperm counts in men, increased incidence of breast cancer and in the testicles, precocious puberty [17]. Besides, hormones can potentially affect the reproductive system of water 
organisms, for example, causing feminization of male fish $[5,18,19,20]$. Due to low levels of contamination and the complexity of environmental matrices requiring the use of methods with high sensitivity and selectivity for the analysis of strogen residues [1, 16, 21], several analytical methods for hormones determination, using liquid chromatography coupled with several types of detectors have been developed. For detection of residual pharmaceuticals in aquatic environment in the range of ng $\mathrm{L}^{-1}$ and $\mu \mathrm{g} \mathrm{L}^{-1}$, the method used in some laboratories are based on solid phase extraction (SPE) and high performance liquid chromatography (HPLC) [22] coupled to a diode array detection [23].

However, in this context, this is the first work dedicated to the determination of hormones in the drinking water supply of the city Piracicaba (Sao Paulo, Brazil). Thus, the main objectives of this paper were (i) analyze and quantify the hormones estriol (E3), 17 $\alpha$-etinilestradiol (EE2) and 17ß-estradiol (E2) in samples of raw and treated water from rivers Piracicaba and Corumbataí using high performance liquid chromatography coupled to a diode array detector (HPLC/DAD), (ii) evaluate if the equipment is suitable to monitor contamination in drinking water and, (iv) adapt and validate the analytical methodology for the analysis of hormones in water samples.

\section{MATERIALS AND METHOdS}

\subsection{Characterization of the study area}

Piracicaba River (Fig. 1) supplies cities that comprise an important industrial and agricultural center and its main contamination is caused by the discharge of wastewater, due to increased population density (over 4 million people), using $95 \%$ of the watershed. Another area of study is the Corumbataí River (Fig. 2), which drains into the Piracicaba River and is also used to supply water to a population of 500,000 inhabitants, including the city of Piracicaba, São Paulo, Brazil. Therefore, studying hormone contamination in these basins has become crucial.

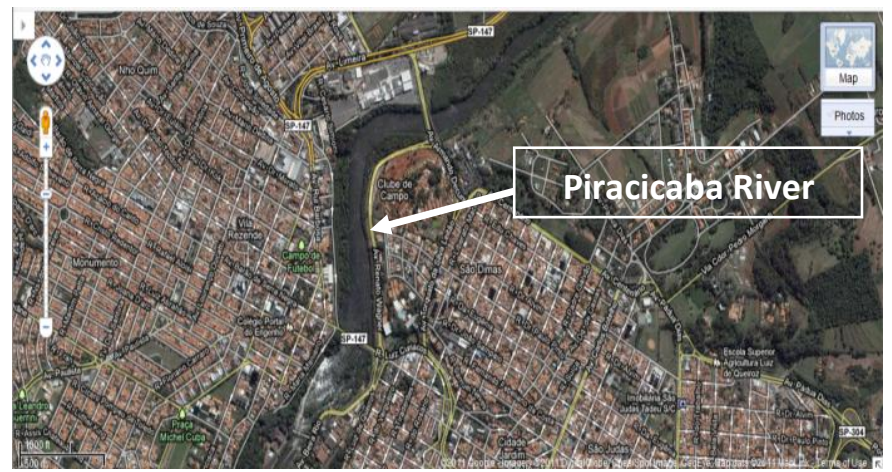

Figure 1. Location of collection point on the Piracicaba River in the city of Piracicaba, São Paulo, Brazil (extracted from Google Maps)

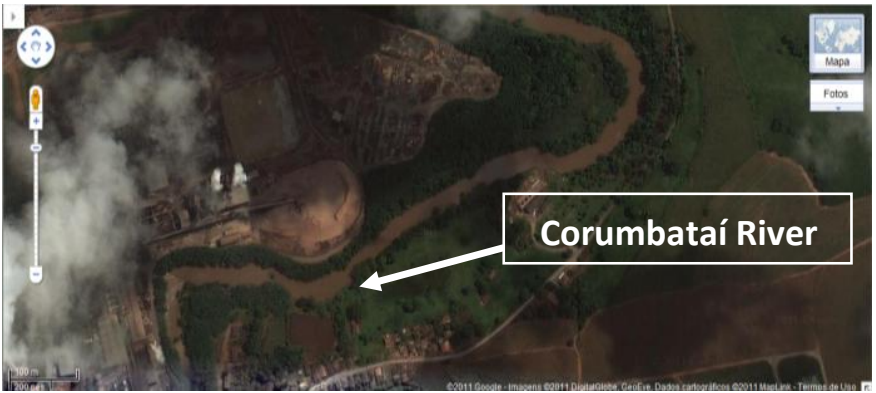

Figure 2. Location of collection point on the Corumbataí

River in the city of Piracicaba, São Paulo, Brazil (extracted from Google Maps)

\subsection{Materials}

Solvents utilized were methanol HPLC grade (MTedia Company, USA) and ultrapure water (Pura-Q, Brazil). The analytical standards used were hormone natural estriol (E3; purity $99.0 \%$ ), hormone synthetic $17 \alpha$-etinilestradiol (EE2; purity $98.5 \%$ ) and natural hormone $17 \beta$-estradiol (E2; purity $99.0 \%$ ), both purchased from Dr. Ehrenstorfer GmbH (Augsburg, Germany) and glass fiber filter $0.47 \mu \mathrm{m}$ (Mackerey-Nagel, Germany).

\subsection{Preparation of standard stock solutions}

Stock solutions from the standards of E3, E2 and EE2 were obtained from the dilution of $10 \mathrm{mg}$ of standards in $10 \mathrm{~mL}$ of methanol and, from the stock solutions, mixed standard of hormones were diluted for the preparation of calibration curve at concentrations of $0.5 ; 1.0 ; 2.0 ; 3.0$ and $4.0 \mathrm{ng} \mathrm{L}^{-1}$. The standard solutions were stored in amber glass vials and placed in a freezer $\left(-20^{\circ} \mathrm{C}\right)$ until the time of use.

\subsection{Apparatus}

Measurements of hormones in water samples were performed by a high chromatograph performance liquid chromatography (Agilent, USA), model 1200 coupled to a diode array detector (DAD), consisting of bomb quaternary, injector manual, degasser, workstation (Agilent ChemStation version B.03.02) for integration data, column Kromasil 100-5C18 $(5 \mu \mathrm{m} \times 4.6 \mathrm{~mm} \times 250 \mathrm{~mm})$, a guard column Kromasil 100-5C18 and a vacuum chamber Visiprep DL (Supelco, USA). The conditions used were previously optimized and adapted [21].

\subsection{Analytical protocols}

The operational conditions of the chromatograph were: column maintained at $40^{\circ} \mathrm{C}$, mobile phase constituted by solvents $\mathrm{A}$ (methanol) and $\mathrm{B}$ (ultrapure water), flow rate of $1.0 \mathrm{~mL} \mathrm{~min}^{-1}$, manual injection of $20 \mu \mathrm{L}$ and wavelength $230 \mathrm{~nm}$. The gradient was $0-12 \min (51 \% \mathrm{~A}$ and $49 \% \mathrm{~B})$, after $12-26 \min (49 \% \mathrm{~A}$ and $51 \% \mathrm{~B})$ and remained under this condition until the end of the chromatographic run.

To determine the efficiency of extraction of solid phase cartridges, cartridge OASIS HLB $500 \mathrm{mg}$ (Waters Corporation, USA) was conditioned with methanol and 
ultrapure water (flow $1.5 \mathrm{~mL} \mathrm{~min}^{-1}$ ), engaged in a vacuum chamber [15]. While the cartridges were conditioned, 200 $\mathrm{ml}$ of sample were filtered through glass fiber filter $(0.45$ $\mu \mathrm{m})$, homogenized in ultrasound and added to a cartridge at a rate of $1.5 \mathrm{~mL} \mathrm{~min}^{-1}$. The cartridges were washed with ultrapure water and dried in a vacuum. The elution was performed with methanol and the eluate was dried in a water bath with $\mathrm{N}_{2}$ and reconstituted with methanol and water $(4 \mathrm{~mL})$ for subsequent HPLC-DAD. For spiked samples, mixed standard was used at concentrations of 1.0, 2.0 and $3.0 \mathrm{ng} \mathrm{L}^{-1}$ (containing E3, EE2 and E2).

\subsection{Collection of samples}

Samples were collected on the surface water, in two points of captures of water at rivers Piracicaba and Corumbataí and treated water at a residence in Piracicaba, São Paulo, Brazil. The samples are collected in triplicate in amber glass bottles of 1 liter each, decontaminated with alkaline soap, running water, deionized water, acetone, solution of $5 \%$ of dimethyldichlorosilane in toluene, dichloromethane and river water before sampling. The bottles were totally filled to minimize contact between water and air, then the flasks were transported to the laboratory and stored in a freezer at $\pm 20^{\circ} \mathrm{C}$ for later extraction and analysis and the samples were collected monthly from November 2007 to April 2009 (every month), totaling 54 samples in 18 months.

\section{RESULTS}

Validation of the proposed method was obtained by evaluating the parameters of selectivity, linearity, repeatability and accuracy. The selectivity of the chromatographic method was evaluated by monitoring the absence of peaks in the regions of hormones retention times. Therefore blank samples (ultrapure water) were injected with and without addition of mixed standard.

Linearity was evaluated by the response obtained as a function of analyte concentration. Analytical standards were prepared in solvent and linearity was determined by the correlation coefficient $\left(\mathrm{r}^{2}\right)$ obtained from the graph relating the equipment response by means of five analyte concentrations and to estimate the coefficients of standard curves, the method of linear regression was used. After the injections, the relative standard deviation (RSD) or coefficient of variation (CV), the estimated standard deviation (s) and linear regression equation of calibration curve for each hormone were determined (Table 1). The process of recovery assays was used to evaluate the accuracy. Ultrapure water samples were spiked and extracted according to the method in section "Analytical protocols", at 1.0, 2.0 and $3.0 \mathrm{ng} \mathrm{L}^{-1}$ and quantified by HPLC-DAD (Table 1).

The linear ranged between $0.5-4.0 \mathrm{ng} \mathrm{L}^{-1}$ for E2, EE2 and E3. Limits of detection (LOD) and limits of quantification (LOQ) were determined by methodology based on parameters of the analytical curve developed by Shabir (2003) and values are demonstrated in Table 1.

Table 1. Values of equations of straights, correlation coefficient and linear range (in $\mathrm{n} \mathrm{L}^{-1}$ ), limits of detection (LOD) and quantification (LOQ), both in $\mathrm{ng} \mathrm{L}^{-1}$, for hormones E3, E2 and EE2.

Hormone Linear equation LOD LOQ

\begin{tabular}{cccc}
\hline E3 & $\mathrm{y}=132.84 \mathrm{x}-5.439$ & 0.1 & 0.5 \\
E2 & $\mathrm{y}=139.35 \mathrm{x}-3.048$ & 0.07 & 0.5 \\
EE2 & $\mathrm{y}=124.44 \mathrm{x}-1.937$ & 0.05 & 0.5 \\
\hline
\end{tabular}

Precision was evaluated by estimating the repeatability through calculating the RSD or CV and the estimated standard deviation (s) resulting from the analysis of seven injections of the mixed standard at a concentration of $1.0 \mu \mathrm{g} \mathrm{L}^{-1}$ under the same operating conditions and in the same day (Table 2).

Table 2. Repeatability of the chromatographic method to determine E3, E2 and EE2.

\begin{tabular}{|c|c|c|c|}
\hline Hormone & Parameter & $\mathrm{Rt}^{*}(\min )$ & $\begin{array}{l}\text { High } \\
(\mathrm{mAu})\end{array}$ \\
\hline \multirow{3}{*}{ E3 } & Mean & 9.2 & 7.14 \\
\hline & $\begin{array}{c}\text { Standard Deviation } \\
(s)\end{array}$ & 11.94 & 0.39 \\
\hline & $\begin{array}{l}\text { Relative Standard } \\
\text { Deviation (RSD) }\end{array}$ & 1.81 & 5.46 \\
\hline \multirow{3}{*}{ E2 } & Mean & 42.3 & 1.93 \\
\hline & $\begin{array}{c}\text { Standard Deviation } \\
(s)\end{array}$ & 8.44 & 0.21 \\
\hline & $\begin{array}{l}\text { Relative Standard } \\
\text { Deviation (RSD) }\end{array}$ & 1.09 & 10.88 \\
\hline \multirow{3}{*}{ EE2 } & Mean & 48.4 & 2.98 \\
\hline & $\begin{array}{c}\text { Standard Deviation } \\
(s)\end{array}$ & 10.59 & 0.24 \\
\hline & $\begin{array}{l}\text { Relative Standard } \\
\text { Deviation (RSD) }\end{array}$ & 0.78 & 8.05 \\
\hline
\end{tabular}

$*$ Rt $=$ Retention time.

The method was selective because for the evaluation of blank sample and matrix spiked with E2, EE2 and E3, there was no interference of eluted compounds at retention times of hormones, and they were well separated from other compounds present in the sample. Retention times for the chromatograms achieved for E3, E2 and EE2, were 9.2, 42.3 and $48.4 \mathrm{~min}$, respectively (Fig. 3). 


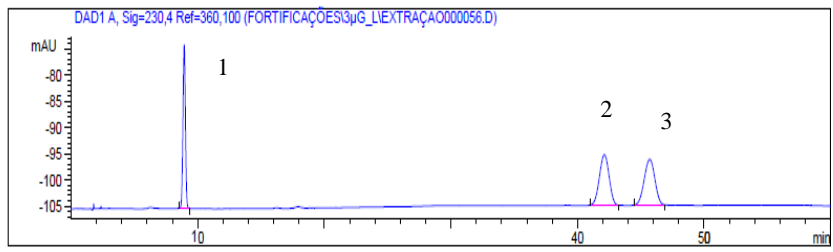

Figure 3. Chromatogram of standards containing estriol (1), $17 \beta$-estradiol (2) and $17 \alpha$-ethinylestradiol (3), analyzed by HPLC-DAD. Retention times for each analyte were (1) 9.2, (2) 42.3 and (3) $48.4 \mathrm{~min}$, respectively.

Linearity of the chromatographic method was achieved by injecting, in triplicate, 5 levels of concentration of mixed standard (containing E3, E2 and EE2) and was observed in the range between 0.5 and $4.0 \mu \mathrm{g} \mathrm{L}^{-1}$ through correlation coefficient $\left(\mathrm{r}^{2}\right)$, which were $0.998,0.998$ and 0.999 for E3, E2 and EE2, respectively. The method denoted low dispersion of data, low uncertainty of the estimated regression coefficients and ideal adjustment data for estimated regression line [24].

Estimation of repeatability of chromatographic method was performed to assess the accuracy of the method. Therefore, the estimates for the absolute standard deviation (s) and RSD or CV were calculated from a mixed standard containing hormones E3, E2 and EE2 of known concentration, which was injected seven times under the same operating conditions and in the same day.

The repeatability of this method was evaluated by some parameters like retention time (in minutes) and high of peaks (mAU). The values of intra-assay precision obtained by the mean, standard deviation and relative standard deviation of measures of retention times and peak heights of analytes are described in Table 2. Considering that the desired results for accuracy, evaluated by $\mathrm{CV}$ obtained, must be less than $15 \%$ [25], the data obtained in the validation of this methodology showed adequate precision, both in the analysis of retention times and in chromatographic peak heights.

Intra-assay precision of the chromatographic peak heights ranged from $5.4 \%$ to E3, $10.8 \%$ to E2 and up to $8.0 \%$ for EE2. The analysis of precision of retention times of the analytes ranged from $1.8,1.0$ and $0.78 \%$ for the E3, E2 and EE2, respectively.

\section{DISCUSSION}

Authors Alda and Barceló (2000) [26], determined the accuracy of the methodology for the determination of hormones by HPLC-DAD and found coefficient of variation greater than $10 \%$ for E3, E2 and EE2, which is slightly above the results obtained in this work, using the same detector diode array detector (DAD). Alda and Barceló (2001) [15] obtained CV from 0.9 to $3.4 \%$ in an inter-assay precision analyzing the same compounds, in this case, the values are higher than those found in this work, because an on-line system was not used to analyze the samples.
The accuracy of the method was evaluated through recovery experiments and the acceptable ranges of recovery for residue analysis are usually between 70 and $120 \%$ accurate to $\pm 20 \%$ [8]. The matrix free from contamination was added to all three hormone concentration standards. The recovery was evaluated by repeating extraction of samples fortified three times at three concentration levels (1.0, 2.0 and $3.0 \mathrm{ng} \mathrm{L^{-1 }}$ ). The data obtained through the injection of the fortifications were used to calculate the standard deviation $(s)$ and $\mathrm{CV}$ and RSD. The recovery values for E3 ranged from 82.5 to $112.3 \%$, for E2 between 91.4 and $100 \%$, and for EE2 between 93.9 and $126.8 \%$. The values obtained are suitable, within the range of acceptable range of recovery for residue analysis, which is between 70 and $120 \%$ accurate to $\pm 20 \%$ [8].

The percentages of recovery of E3 and E2 in the samples of ultrapure water spiked with mixed standard of $3.0 \mathrm{ng} \mathrm{L}{ }^{-1}$, reached a value of $97 \%$ and $100 \%$ respectively, They were close to those found by Wang et al. (2008) [21], which used the same concentration of fortification in raw water samples of river and obtained values of $91 \%$ for E3 and $99 \%$ for E2, using cartridge for solid phase extraction (SPE).

Alda and Barceló (2001) [15] obtained recovery percentages from 99, 97 and 97\% for hormones E3, E2 and EE2, respectively, using the same type of cartridge, sample volume spiked and concentration of analytes of interest. In the current study, the values of each analyte recovery were very close to those found by [15].

The LOD and LOQ were calculated using the analytical curve for each hormone and there were significant differences between LD values for compounds E3 and the others (EE2 and E2). However, this may be attributed to the fact that this molecule presents chemical bonds that make it less detectable by the diode array detector. The detection limits for the compounds are below the limits founded by Almeida and Nogueira (2006) [23] (50 $\mathrm{g} \mathrm{L} \mathrm{L}^{-1}$ for $\mathrm{E} 2$ and $300 \mu \mathrm{g} \mathrm{L} \mathrm{L}^{-1}$ for EE2) for these two compounds.

Therefore, at the end of validation methodology, the samples were collected and subsequently the method was applied. The raw and treated water samples collected ( $\mathrm{n}$ = 54) were applied to the methodology adapted and validated and the method did not detect any contamination with the target hormones used in this study (E3, E2 and EE2). It is possible that during the collection period, samples were not contaminated and the contact of water treated with chlorine residual could mitigate potential contaminants in the water, knowing that it degrades these substances [27]. Fig. 4 illustrates the chromatogram of a sample of the Corumbataí River.

\section{CONCLUSION}

So it is concluded that the chromatographic method SPE and HPLC/DAD proposed for detection and quantification of hormones E3, E2 and EE2 is specific and 
IOSR Journal of Engineering

May. 2012, Vol. 2(5) pp: 984-989

linear (concentration range 0.5 to $4.0 \mathrm{ng} \mathrm{L}^{-1}$ ) and the values of detection and quantification limits were suitable for the analysis of hormones in water samples. This methodology also showed characteristics such as simplicity and reliability, which has potential for application in routine laboratory analysis of hormones E3, E2 and EE2 in aqueous samples. However, no contamination by hormones was detected in 18 samples of raw and 36 samples of treated water from the Piracicaba and Corumbataí Rivers.

\section{ACKNOWLEDGEMENTS}

The authors would thanks for support given by CAPES, CNPq and Fapesp.

\section{REFERENCES}

[1] P Verlicchi, A. Galletti, M. Petrović and D. Barceló, Hospital effluents as a source of emerging pollutants: An overview of micropollutants and sustainable treatment options. Journal of Hydrology, 389 (3-4), 2010, 416-428.

[2] R López-Serna, S. Pérez, A. Ginebreda, M. Petrović and D. Barceló, Fully automated determination of 74 pharmaceuticals in environmental and waste waters by online solid phase extraction-liquid chromatography-electrospray-tandem mass spectrometry. Talanta, 83 (2), 2010, 410-424.

[3] A Ginebreda, I. Muñoz, M.J.L. Alda, R. Brix, J. López-Doval and D. Barceló, Environmental risk assessment of pharmaceuticals in rivers: Relationships between hazard indexes and aquatic macroinvertebrate diversity indexes in the Llobregat River (NE Spain). Environment International, 36 (2), 2010, 153-162.

[4] MS Díaz-Cruz, M.J.L. Alda and D. Barceló, Environmental behavior and analysis of veterinary and human drugs in soils, sediments and sludge. Trends in Analytical Chemistry, 22 (6), 2003, 340351.

[5] KA Kumar, S.V. Mohan and P.N. Sarma, Sorptive removal of endocrine-disruptive compound (estriol, E3) from aqueous phase by batch and column studies: Kinetic and mechanistic evaluation. Journal of Hazardous Materials, 164 (2-3), 2009, 820-828.

[6] MS Diniz, R. Maurício, M. Petrović, M.J.L. Alda, L. Amaral, I. Peres, D. Barceló and F. Santana, (2010) Assessing the estrogenic potency in a Portuguese wastewater treatment plant using an integrated approach. Environmental Science \& Technology, 22 (10), 2010, 1613-1622.

[7] C Desbrow, E.J. Routledge, G.C. Brighty, J.P. Sumpter and M. Waldock, Identification of estrogenic chemicals in STW effluent. 1. Chemical fractionation and in vitro biological screening. Environmental Science \& Technology, 32 (11), 1998, 1549-1558.

[8] TA Ternes, M. Stumpf, J. Mueller, K. Haberer, R.D. Wilken and M. Servos, Behavior and occurrence of estrogens in municipal sewage treatment plants - I. Investigations in Germany, Canada and Brazil. Science of the Total Environment, 225 (1-2), 1999, 81-90.

[9] S Hartmann, M. Lacorn and H. Steinhart, Natural occurrence of steroid hormones in food. Food Chemistry, 62 (1), 1998, 7-20.

[10] M Bodzek and M. Dudziak, Elimination of steroidal sex hormones by conventional water treatment and membrane processes. Desalination, 198 (1-3), 2006, 24-32.

[11] GG Ying, R.S. Kookana and Y.J. Ru, Occurrence and fate of hormones steroids in environment. Environment International, 28 (6), 2002, 545-551.

[12] JA Russell, R.K. Malcolm, K. Campbell and A.D. Woolfson, High-performance liquid chromatographic determination of $17 \beta$-estradiol and 17 $\beta$-estradiol-3acetate solubilities and diffusion coefficients in silicone elastomeric intravaginal rings. Journal of Chromatography B 744 (1), 2000, 157.

[13] M Gros, M. Petrović, A. Ginebreda and D. Barceló, Removal of pharmaceuticals during wastewater treatment and environmental risk assessment using hazard indexes. Environment International, 36 (1), 2010, 15-26.

[14] M Solé, D. Raldua, D. Barceló and C. Porte, Longterm exposure effects in vitellogenin, sex hormones, and biotransformation enzymes in female carp in relation to a sewage treatment works. Ecotoxicology and Environmental Safety, 56 (3), 2003, 373-380.

[15] MJL Alda and D. Barceló, Use of solid-phase extraction in various of its modalities for sample preparation in the determination of estrogens and progestogens in sediment and water. Journal of Chromatography A, 938 (1-2), 2001, 145-153.

[16] M Kuster, S.D. Cruz, M. Rosell, M.J.L. Alda and D. Barceló, Fate of selected pesticides, estrogens, progestogens and volatile organic compounds during artificial aquifer recharge using surface waters. Chemosphere, 79 (8), 2010, 880-886.

[17] XY Xiao, D.V. McCalley and J. McEvoy, Analysis of estrogens in river water and effluents using solidphase extraction and gas chromatography-negative chemical ionization mass spectrometry of the pentafluorobenzoyl derivatives. Journal of Chromatography A, 923 (1-2), 2001, 195-204.

[18] AD Pickering and J.P. Sumpter, Comprehending endocrine disrupters in aquatic environments: additional projects arose from a three-year, multinational, multidisciplinary research program in the European Union. Environmental Science \& Technology, 1(17), 2003, 331-336.

[19] JP Sumpter, Endocrine disrupters in the aquatic environment: an overview. Acta Hydrochimica et Hydrobiologica 33 (1), 2005, 9-16. 
IOSR Journal of Engineering

May. 2012, Vol. 2(5) pp: 984-989

[20] E Vine, J. Shears, R.V. Aerle, C.R. Tyler, J.P. Sumpter, Endocrine (sexual) disruption is not a prominent feature in the pike (Esox Lucius), a top predator, living in English waters. Environmental Toxicology \& Chemistry, 24 (6), 2005, 1436-1443.

[21] S Wang, W. Huang, G. Fang, J. He andY. Zhang, Online coupling of solid phase extraction to highperformance liquid chromatography for determination of estrogens in environment. Analytica Chimica Acta, 606 (2), 2008, 194-201.

[22] T Isobe, H. Shiraishi, M. Yasuda, A. Shinoda, H. Suzuki and M. Morita, Determination of estrogens and their conjugates in water using solid-phase extraction followed by liquid chromatographytandem mass spectrometry. Journal of Chromatography A, 984 (2), 2003, 195-202.

[23] C Almeida and J.M.F. Nogueira, Determination of steroid sex hormones in water and urine matrices by stir bar sorptive extraction and liquid chromatography with diode array detection. Journal of Pharmaceutical and Biomedical Analysis, 41 (1), 2006, 1303-1311.

[24] JM Green, A practical guide to analytical method validation. Analytical Chemistry, 68 (3), 1996, A305A309.
[25] GA Shabir, Validation of high-performance liquid chromatography methods for pharmaceutical analysis. Understanding the differences and similarities between validation requirements of the US Food and Drug Administration, the US Pharmacopeia and the International Conference on Harmonization. Journal of Chromatography A, 987 (1-2), 2003, 57-66.

[26] MJL Alda and D. Barceló, Determination of steroid sex hormones and related synthetic compounds considered as endocrine disrupters in water by liquid chromatography-diode array detection-mass spectrometry. Journal of Chromatography A, 911 (2), 2000, 203-210.

[27] RT Verbinnen, G.S. Nunes and E.M. Vieira, Determination of estrogens hormones in drinking water using HPLC-DAD. Química Nova, 33 (9), 2010, 1837-1842. 